\title{
The effect of food location, heat load, and intrusive medical procedures on brushing activity in dairy cows
}

\author{
R. Mandel, ${ }^{1}$ H. R. Whay, † C. J. Nicol, $†$ and E. Klement ${ }^{*}$ \\ ${ }^{*}$ Koret School of Veterinary Medicine, Robert H. Smith Faculty of Agriculture, Food and Environment, The Hebrew University, \\ Rehovot 76100, Israel \\ †Department of Clinical Veterinary Science, Langford House, Langford, University of Bristol, Bristol BS18 7DU, UK
}

\section{ABSTRACT}

Animals allocate time and effort to a range of core (e.g., sleeping, feeding, drinking) and "luxury" (e.g., playing, exploring) activities. A luxury activity is characterized by low resilience and, as such, will be reduced when time or energy resources are limited, including under conditions of stress or discomfort. One seemingly luxurious activity available to cows on an increasing number of dairy farms is rubbing against an automated brush. The current study examined the effect of distance from food, heat load, and an intrusive medical procedure (i.e., artificial insemination and transrectal pregnancy examination) on the resilience of brush usage. The probability of using the brush decreased significantly when food was located distantly from the brush (mean $=0.53)$ compared with days when food was located closer to the brush (mean $=0.81$ ). Brush usage also decreased at high temperature and humidity levels, with an average decrease of 0.062 brushing events for an increase of 1 temperature-humidity index unit $(95 \%$ confidence interval $=-0.93-0.030)$. In addition, a significant reduction of approximately $50 \%$ in brushing activity was observed on days of artificial insemination compared with the preceding $3 \mathrm{~d}$ and the following $3 \mathrm{~d}$. These findings show that brush usage is a low resilience activity that reduces under a range of conditions. It may thus have the potential to be used as an indicator of a range of health and welfare problems in cows. Further research should be conducted to assess the sensitivity and specificity of this suggested tool and its possible contribution to the early detection of morbidity.

Key words: mechanical brush, welfare, stress, anhedonia

Received April 19, 2013.

Accepted June 29, 2013

${ }^{1}$ Corresponding author: roi.mandel@mail.huji.ac.il

\section{INTRODUCTION}

In the mid-1980s, automatic cow brushes activated by the animals were developed from the first equipment that featured simple sprung brushes (Georg and Totschek, 2001). An increasing number of dairy farmers now choose to install automatic brushing devices and, in some countries, it is considered standard equipment in a freestall barn (Georg et al., 2007). Some farmers install the brushes mainly for husbandry reasons such as helping the cows stay clean and increasing milk yield (Schukken and Young, 2009), whereas others emphasize the hedonic role of the brush in enriching the cows' environment (Wilson et al., 2002) and serving as a replacement for the scratching tree on pasture (Georg and Totschek, 2001). These authors showed that an automated brush makes it easier for cows to groom themselves, particularly in body regions that they find hard to reach. Another study found that cows increased the time spent scratching by $508 \%$ and the frequency of scratching events by $226 \%$ when an automatic brush was introduced to the cows compared with scratching on pen objects (DeVries et al., 2007). High utilization rates have also been recorded around the time of calving (Newby et al., 2013) and in calves (Georg et al., 2007). Although cows tend to use the brush for only a limited time each day, competition for this resource has been recorded. In one study, frequency of displacements at the brush was 6 times greater compared with displacements at the feeder when adjusted for time of use (Val-Laillet et al., 2008).

The increasing prevalence of brush installation on dairy farms provides a platform to investigate the utility of monitoring brush usage patterns as a management tool. One of the possible implementations of such a tool is the detection of stress and morbidity. Weary et al. (2009) suggested that behaviors that offer only longer-term fitness will be most likely to decline with illness, as animals divert resources to those functions of critical short-term value, such as maintaining body temperature. Maintenance (e.g., grooming) and sexual behaviors, although ultimately of key value to the animal, were considered to be less urgent, at least under 
some conditions (Weary et al., 2009). The extent to which activity can be suppressed in terms of time by other activities in the animal's repertoire was previously referred to as "behavioral resilience" (McFarland, 1999). Resilience can be measured indirectly by means of demand functions, which express the relationship between the price and the consumption of a commodity (Dawkins, 1990; Fraser and Nicol, 2010); for example, the distance an animal is willing to walk to approach food (Verbeek et al., 2011).

A luxury activity is characterized by low resilience (McFarland, 1999) and, as such, is expected to be reduced when time or energy resources are limited or when the cost involved in the activity increases. Because grooming behaviors in cattle show low resilience (Borderas et al., 2008; Fogsgaard et al., 2012; but see also opposing findings by Almeida et al., 2008), we predict that brush usage may fall under the category of luxury activity, and thus be reduced when the cost for utilizing the brush increases or when energy resources are limited.

Another factor that might contribute to a reduction of brush usage in states of stress and morbidity is anhedonia; that is, the reduced capacity to experience pleasure, typically measured in terms of the decreased consumption of rewards (Meagher and Mason, 2012). Cabib and Puglisi-Allegra (1996) suggested that exposure to unavoidable or uncontrollable aversive experiences leads to an impaired response to rewarding stimuli (anhedonia). Therefore, a reduction in brush usage during stress and morbidity can be explained either by anhedonia or by energy cost when the effort involved in utilizing the brush exceeds a certain threshold.

The current study serves as the first phase in assessing the possible utilization of brush usage as an indicator of stress and morbidity by exploring the resilience of brush usage in face of different stressors. Previous studies suggest that both heat load (Collier and Zimbelman, 2007) and an intrusive medical procedure (Fischer-Tenhagen et al., 2012) increase stress levels in dairy cows. Increased stress, like increased morbidity, consumes energy resources (Moberg, 2000) and may be associated with increased effort of locomotion. We thus hypothesize that brush usage will be reduced when food is distant from the brush, at high temperature and humidity levels, and on the day of an intrusive medical procedure. If brush usage is confirmed as a low resilience activity, then it could be used as a sensitive indicator of stress or morbidity at both the herd and the individual levels and could serve as an early-warning indicator of health and welfare problems in dairy cows.

Finding a good behavioral early indicator of morbidity could be especially useful in improving the welfare of dairy cows and allowing better treatment, thus re- ducing suffering and distress (Littin et al., 2008; Weary et al., 2009; Relić et al., 2012). Brushing activity might fit the profile of a good indicator because it could be measured objectively and may evolve to fit the requirement of being a valid, reliable, and feasible automated measure of a behavior-based animal welfare indicator (Rushen et al., 2012).

\section{MATERIALS AND METHODS}

\section{Study Population}

A total of 40 Holstein dairy cows participated in this study (the group size increased from 37 to 40 during the course of the experiment). All cows were in their second lactation. The cows were housed together in a 55- $\times 19-\mathrm{m}$ loose house bedded with dried manure. Individual cows were identified by a unique 3- or 4-digit code branded on their body at a younger age. The average DIM at the beginning of the data collection was 186.7 (SD 65.9). The average cow's milk yield over the course of the experiment was $38.2 \mathrm{~kg} / \mathrm{d}$ (SD 8.7).

Cows were fed once a day between 0800 and 0900 $\mathrm{h}$ on the southwest side of the cowshed, where the brush was installed (Figure 1, side A), or opposite to the brush location (northeast side, side B), or on both sides of the cowshed $(\mathrm{A}+\mathrm{B})$. The average distances of food from the brush across each side of the cowshed were $15.36,20.51$, and $18.08 \mathrm{~m}$, respectively. Delivery of food to different sides of the cowshed on different days of the week was done to help dry the soil as part of the cultivation process practiced in the Israeli dairy farm system. During weekdays, the location of food distribution varied between side $\mathrm{A}$ and side $\mathrm{B}$, depending on soil condition. During weekends (Friday and Saturday), food was distributed on both sides of the cowshed.

Cows were fed with a mixture of 9.4 to $14.4 \%$ grained corn, 5.1 to $9.2 \%$ corn gluten feed, 1.6 to $3.8 \%$ sunflower pulp, $2.2 \%$ rape pulp, up to $6.1 \%$ grain hay, 2.2 to $5 \%$

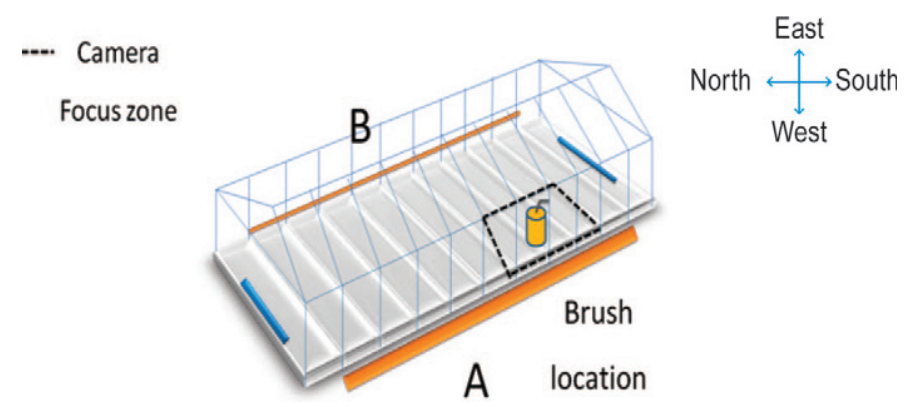

Figure 1. Experimental arena. Cows were fed once a day on the southwest side where the brush was positioned (A), or opposite the brush location (B), or on both sides of the cowshed. Color version available in the online PDF. 
grained wheat, 8.3 to $16.8 \%$ wheat oxide, $2.2 \%$ wheat straw, 0.4 to $0.5 \%$ calcium carbonate, 3.9 to $5.6 \%$ dried distillers grains with solubles, 1.1 to $2.8 \%$ soy molasses, $0.2 \%$ salt, 0.5 to $0.6 \%$ sodium bicarbonate, $9.7 \%$ moist corn waste, 13 to $17.5 \%$ soy fibers, and 14 to $19.9 \%$ corn straw.

Food was pushed closer on average 2 times a day (SD 1.17). Video analysis showed that food was available in the feeding trough until approximately 0300 to $0400 \mathrm{~h}$ on the following day. Cows were milked 3 times per day, at 0430 to $0530 \mathrm{~h}, 1200$ to $1300 \mathrm{~h}$, and 2000 to $2100 \mathrm{~h}$. The time cows were absent from the cowshed for each milking ranged from 20 to $60 \mathrm{~min}$.

\section{Brushing Activity}

An automatic swinging brush (swinging cow brush SCB, DeLaval International AB, Tumba, Sweden) was installed $1 \mathrm{~d}$ before the beginning of the study on the southwest side of the shed (Figure 1, side A). The brush was equipped with a pivoting arm that enabled it to move in different directions. When mechanical pressure was applied to the brush, the brush started revolving at a speed of $26 \mathrm{rpm}$, enabling the cow to stand and be brushed with no extra effort invested. Once activated, the brush continued to rotate for 10 seconds after the cow departed. A cow was considered to be using the brush either when she approached the brush, touched it, and was brushed automatically for a period of more than $3 \mathrm{~s}$, or when she actively rubbed any part of her body on the brush (not necessarily activating the automatic rotation function).

Brushing activity was recorded for a period of $56 \mathrm{~d}$ using 2 high-resolution video cameras (Provision ISR I3-370CSVF; Provision ISR, Shekou, Shenzhen, China) connected to a digital video recorder (Provision ISR SA-16400HD). Each camera was equipped with 64 infrared light-emitting diodes, which enabled the system to record continuously $(24 \mathrm{~h} / \mathrm{d})$ using motion detection sensors.

\section{Data Encoding}

Each day (24-h period) was divided into 288 intervals of 5 min each. During each interval, the identity of cows that used the brush was recorded. The cows used the brush one after the other or simultaneously (up to 3 cows at a time). Temperature and humidity data were collected at a regional meteorological station located $6 \mathrm{~km}$ from the farm (Gimzo meteorological station, Meteorological Department, Ministry of Agriculture and Rural Development, Gimzo, Israel). Temperaturehumidity index (THI) was calculated as follows:

$$
\begin{gathered}
\mathrm{THI}=\operatorname{Tmax}\left({ }^{\circ} \mathrm{F}\right)-\{[0.55-0.55 \times(\mathrm{RHmin} / 100)] \\
\left.\times\left[\operatorname{Tmax}\left(\mathrm{F}^{\circ}\right)-58\right]\right\},
\end{gathered}
$$

where Tmax $=$ daily maximum temperature, and $\mathrm{RH}-$ min $=$ daily minimum relative humidity (Ominski et al., 2002).

\section{Stressful Manipulation}

We used the Israeli management information system for the national dairy and beef herds (NOA; Israel Cattle Breeders Association, Caesarea, Israel) to identify dates of routine intrusive medical procedures (transrectal pregnancy examinations and AI). We compared the daily number of brushing events per cow on the day of intrusive manipulation, on the preceding $3 \mathrm{~d}$, and on the following $3 \mathrm{~d}$. A total of 27 intrusive medical procedures were included in this analysis (17 AI and 10 pregnancy examinations). Two cows included in this analysis underwent both AI and pregnancy examination. On the return from the morning milking, cows that were scheduled to go through a pregnancy examination or AI were separated from the group and taken to a different cowshed, where they waited $3 \mathrm{~h}$ until the procedure began. During this time, cows had free access to food. Cows that went through the AI procedure were also provided with water. The AI or pregnancy examination of all cows involved lasted no more than 30 min, depending on the number of cows that underwent the procedure, after which the cows were returned to the main shed. During the procedure and the preceding $3 \mathrm{~h}$, cows did not have the opportunity to use the brush. This time period was therefore excluded from analysis, together with parallel periods in the $3 \mathrm{~d}$ preceding the procedure and the $3 \mathrm{~d}$ following it. This was performed to compare similar periods in the procedure day and the control days. In addition, we excluded all pregnancy examinations that were followed by medical treatment. This was done to avoid possible influence of drugs or morbidity on brushing behavior.

\section{Statistical Analysis}

Brushing Activity over 56 d. Three days were excluded from this analysis because of a technical problem with the camera recording system. Brushing activity was analyzed using 2 different cow-level outcome variables: (1) daily probability of using the brush at least once; and (2) daily average number of brushing events. To overcome the lack of independence between daily measures within each cow, the effect of food location and THI on brushing activity was examined using a generalized estimating equation (GEE) regression 
model (IBM SPSS Statistics for Windows, version 21.0. IBM Corp., Armonk, NY) with an exchangeable covariance structure for the working matrix (i.e., correlation between average daily number of brushing events and the probability of using the brush within cow but not between cows). The number of brushing events was examined using an identity link function (linear model), whereas the binary outcome (brushing at least once a day vs. no brushing) was examined using the logit link function (logistic model). Specifically, to examine the effect of food location on brushing activity, we used food location as a 3-level nominal factor in the GEE model (on the brush side, opposite to the brush, and on both sides of the cowshed). The effect of THI on brushing activity was examined during daylight hours (0600-1800 h) and nighttime hours (1800 to $0600 \mathrm{~h}$ on the following day) after stratifying the days by food location (THI was defined as a covariate). The effect of THI on the average daily number of brushing events was assessed using Pearson correlation procedure using a similar stratification of the data as in the GEE model.

Effect of Intrusive Medical Procedure. The effect of the intrusive medical procedure on brushing activity was examined using a repeated-measures ANOVA comparing the daily number of brushing events per cow on the day of the intrusive manipulation, the preceding $3 \mathrm{~d}$, and the following $3 \mathrm{~d}$.

\section{RESULTS}

\section{Brush Utilization}

The average daily proportion of cows that used the brush at least once was $0.70(\mathrm{SD}=0.46$; minimum 0.53 , maximum 0.95). On average, cows used the brush 4.5 times per day $(\mathrm{SD}=5.78$; minimum 0 , maximum 45). Brushing activity increased throughout the day, peaking around $1800 \mathrm{~h}$.

\section{Food Location}

Food location was significantly associated with the probability of using the brush (Figure 2). Brush usage probability was $0.81(95 \% \mathrm{CI}=0.70$ to 0.88$)$ when food was available on the brush side, $0.68(95 \%$ CI $=$ 0.57 to 0.77 ) when food was available on both sides, and $0.53(95 \% \mathrm{CI}=0.45$ to 0.61$)$ when it was available on the side opposite the brush. All of these differences were statistically significant $(P<0.01$; Figure $2 \mathrm{a})$. The average number of brushing events on days when food was available on the brush side (mean $=6.56,95 \%$ CI $=5.01$ to $8.11 ; P<0.01)$ was significantly higher than on days when food was available on both sides of the cowshed $($ mean $=4.38,95 \% \mathrm{CI}=3.05$ to $5.72 ; P<$ a)
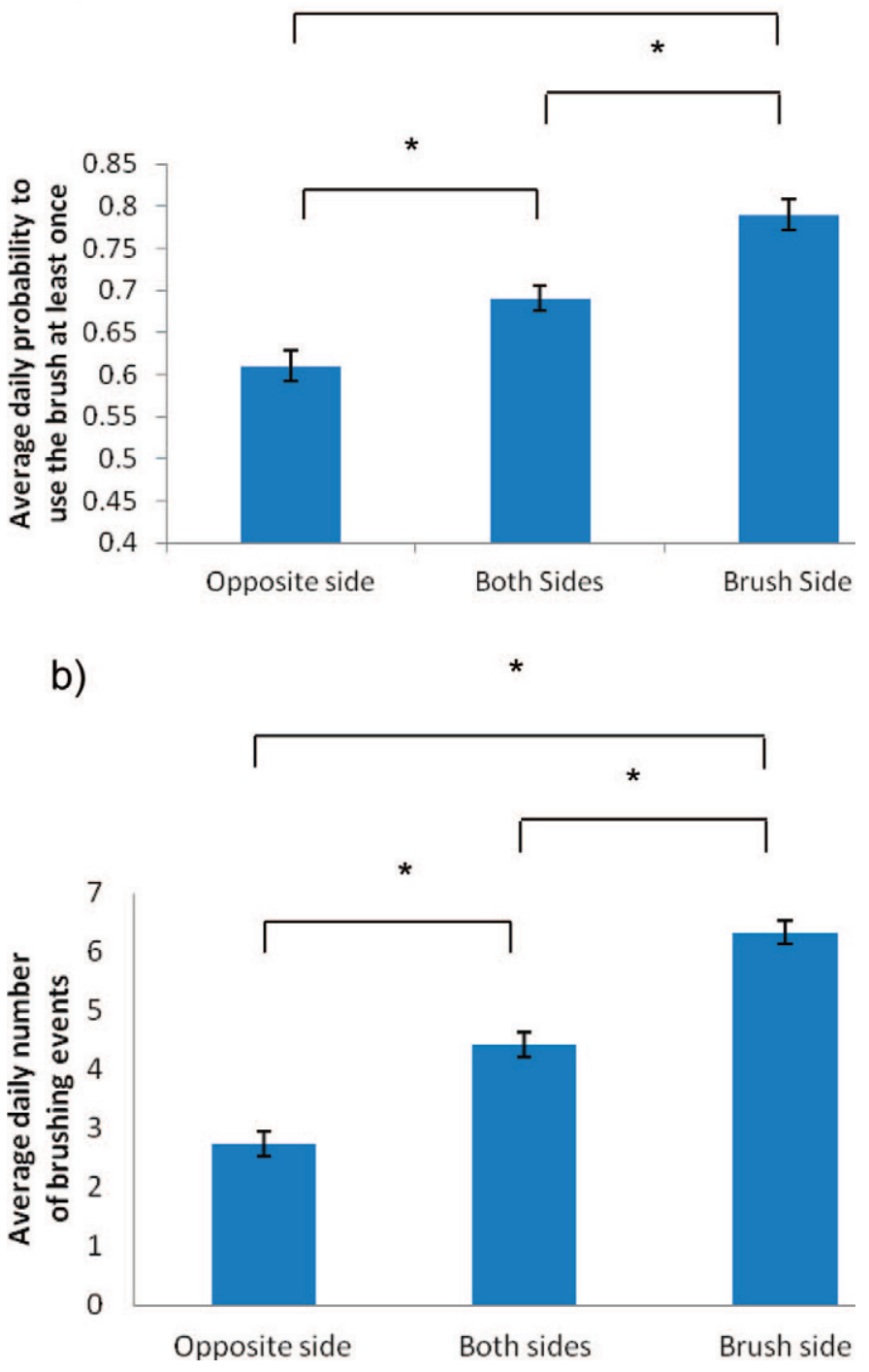

Figure 2. The effect of food location on brushing activity: (a) average daily probability of using the brush at least once (bars represent standard error of the means); (b) daily average brushing events per cow. Both measures were significantly higher on days when food was available on the brush side compared with days when food was available on the opposite side and on both sides of the cowshed. ${ }^{*} P<0.01$. Color version available in the online PDF.

0.01) or on the opposite side of the cowshed (mean $=$ $2.47,95 \% \mathrm{CI}=1.63$ to 3.31 ; Figure $2 \mathrm{~b}$ ).

\section{Temperature and Humidity}

Throughout the course of the experiment, THI ranged from 56 to $77(68.7 \pm 4.6$; mean $\pm \mathrm{SD})$. The effect of THI on brush usage varied between day and night according to the distance of the food from the brush. During the daytime (0600-1800 h) on days when food was available on the side opposite to the brush, 
THI was found to be negatively correlated with the average daily number of brushing events $(\mathrm{r}=-0.79$, $\mathrm{n}=18 ; P<0.01)$. We did not find a significant correlation between THI and the average daily number of brushing events on days when food was available on both sides of the cowshed $(\mathrm{r}=-0.30, \mathrm{n}=17 ; P=0.25)$ or when food was available on the brush side $(\mathrm{r}=0.32$, $\mathrm{n}=18 ; P=0.20)$. During the nighttime $(1800-0600 \mathrm{~h})$, THI was correlated with the average daily number of brushing events only on days when food was available on the brush side $(\mathrm{r}=0.74, \mathrm{n}=18 ; P<0.01$; Figure $3)$. When a correction for within-subject correlations was applied by assuming a priori a correlation structure for the repeated measurements (GEE model), THI was negatively correlated with the number of brushing events on days when food was available opposite to the brush side and on both sides of the cowshed. On these days, an average decrease in brushing events of -0.067 $(95 \% \mathrm{CI}=-0.105$ to $-0.029 ; P<0.01)$ and -0.053 (95\% CI $=-0.114$ to $0.007 ; P=0.08)$, respectively, was observed for an increase of 1 THI unit. The number of brushing events was not significantly associated with THI on days when food was available on the brush side $(P=0.261)$. During nighttime $(1800-0600 \mathrm{~h})$, a contrast effect was observed: on days when food was available on the brush side, a significant positive association was found between THI and brushing events, with an average increase of $0.090(95 \% \mathrm{CI}=0.038$ to $0.142 ; P<0.01$ ) for an increase of 1 THI unit. We did not find a significant association between THI levels and the number of brushing events during the night on days when food was available on the opposite side of the cowshed and on both sides of the cowshed (Table $1)$.

\section{Intrusive Medical Procedures}

A repeated-measures ANOVA revealed a significant effect of intrusive medical procedures on brushing activity $\left(\mathrm{F}_{2,52}=3.26 ; P<0.05\right)$. Planned contrasts revealed marginally significant differences in the predicted direction: the number of brushing events on the day of intrusive procedure $(3.11 \pm 2.88$; mean $\pm \mathrm{SD})$ was lower compared with that on the previous $3 \mathrm{~d}(4.80 \pm 5.16$, $\mathrm{t}_{26}=1.99$, where $\mathrm{t}$ represents a paired-samples $t$-test with the df as a subscript; $P=0.051$ ) and the following $3 \mathrm{~d}\left(4.86 \pm 4.93, \mathrm{t}_{26}=2.05, P=0.057\right)$. When separating the different types of intrusive medical procedure (pregnancy examination vs. AI), we found that the reduction in brushing events remained significant following $\mathrm{AI}\left(\mathrm{F}_{2,32}=4.71 ; P<0.05\right)$. Specifically, brushing events on the day of AI were significantly lower $(2.24 \pm$ 2.11) compared with the previous $3 \mathrm{~d}\left(4.82 \pm 5.89, \mathrm{t}_{16}\right.$ $=2.14 ; P=0.048)$ and the following $3 \mathrm{~d}(5.04 \pm 5.63$, $\mathrm{t}_{16}=2.53 ; P=0.022 ;$ Figure $\left.4 \mathrm{a}\right)$. However, the effect of pregnancy examination was not significant $\left(\mathrm{F}_{2,18}<\right.$ 1, Figure 4b).

\section{DISCUSSION}

The introduction of automated brushing devices in the dairy farm industry has been accompanied by several studies investigating the brushing habits of dairy cows (Georg and Totschek, 2001; DeVries et al., 2007; Georg et al., 2007; Val-Laillet et al., 2008; Newby et al., 2013) and the possible contribution of the brush to cows' cleanliness and milk yield (Schukken and Young, 2009). To our knowledge, the current study is the first to monitor routine brushing activity of dairy cows with the aim of identifying behavioral changes indicative of stress and discomfort. Brushing activity was found to decrease when food was located farther from the brush, at high THI, and following an intrusive medical procedure. The elastic demand for brushing activity when food was located farther from the brush, during heat load, and following an intrusive procedure may therefore support the potential future use of this tool at identifying stress and discomfort at both the herd level and the individual level. One seeming limitation of this tool is the variance in utilization rates of the brush. The average daily proportion of cows that used the brush at least once a day ranged from 0.46 to 0.95 , with an average daily proportion of 0.70 . Monitoring brush usage to detect stress and morbidity might therefore be useful only for cows that use the brush on a regular basis.

Location of food relative to the brush had a major effect on the daily probability of using the brush and the average number of brushing events per cow. The daily average number of brushing events decreased by $62 \%$ on days when food was available opposite to the brush compared with days when food was available on the brush side. This finding corresponds with the previous suggestion that behaviors with a primary function of promoting the survival of the individual will take precedence over behaviors that promote other aspects of fitness (McFarland, 1999) - in this case, the precedence of feeding over the use of a mechanical brush.

Additional support for this idea comes from the effect of THI on brushing activity. On days when food was located farther from the brush (i.e., when food was spread on the opposite side of the cowshed or on both sides), THI was negatively associated with brushing activity. This was observed only during daytime hours, when THI levels reached peak value. At a combination of distance and high THI level, approaching the brush would require more effort than cows may be willing 
Table 1. The effect of elevation in 1 temperature-humidity index (THI) unit on the number of brushing events during daytime and nighttime using a generalized estimating equation (GEE) model

\begin{tabular}{|c|c|c|c|c|c|c|c|}
\hline Food location & \multicolumn{3}{|c|}{ Day (0600-1800 h) } & \multicolumn{3}{|c|}{ Night (1800-0600 h) } & $\begin{array}{c}\text { No. of } \\
\text { observations }^{1}\end{array}$ \\
\hline Both sides & -0.053 & 0.082 & -0.114 to 0.007 & 0.028 & 0.381 & -0.035 to 0.092 & 563 \\
\hline Brush side & 0.061 & 0.261 & -0.045 to 0.166 & 0.090 & 0.001 & 0.038 to 0.142 & 720 \\
\hline
\end{tabular}

${ }^{1}$ The total number of observations is the cumulative number of daily measurements (approximately the number of cows multiplied by the number of observation days).

${ }^{2}$ Regression coefficient.

to invest. Under these conditions, given limited energy reserves, it might be more beneficial for cows to invest in core activities such as eating and reducing body temperature rather than brushing activity. During the nighttime, however, we saw a different pattern. Following days when food was available on the brush side, we observed a significant positive association between THI and brush usage.
Day time

(06:00-18:00)

Opposite to brush

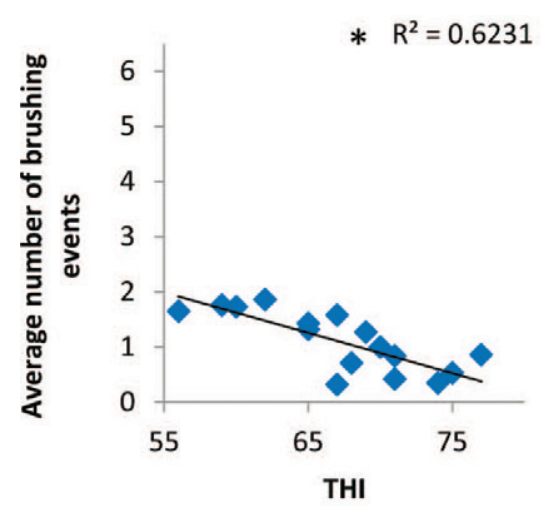

THI

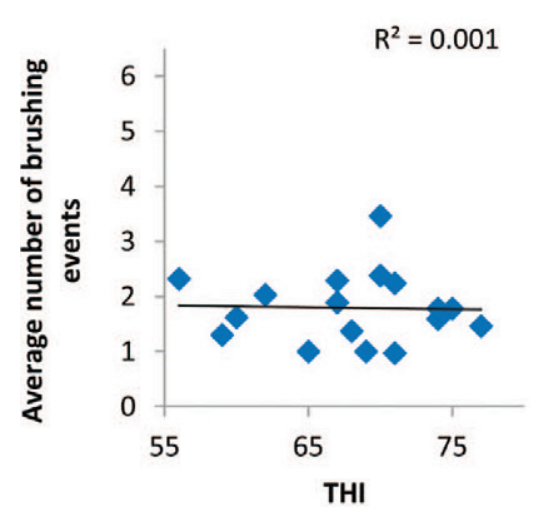

Both sides

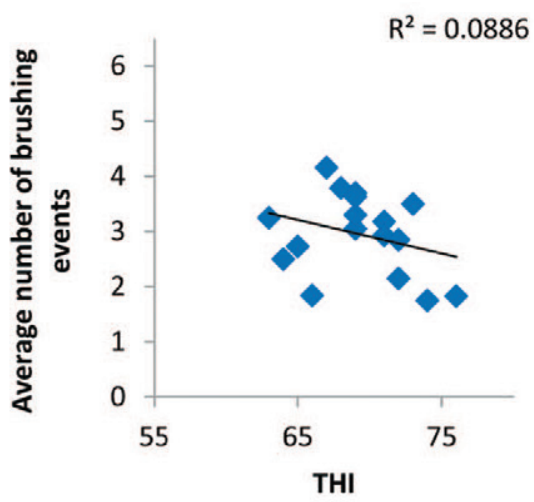

Night time

(18:00-06:00)

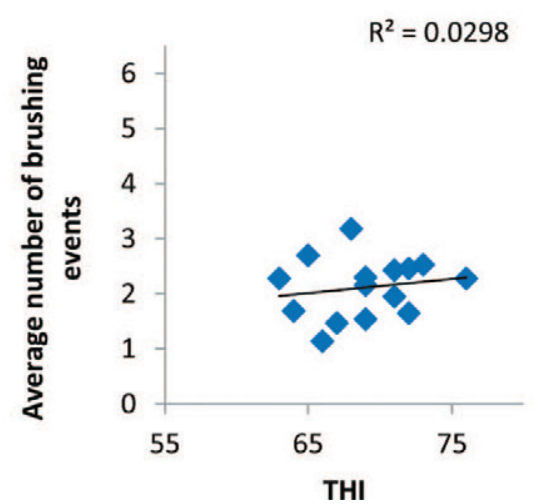

Brush side
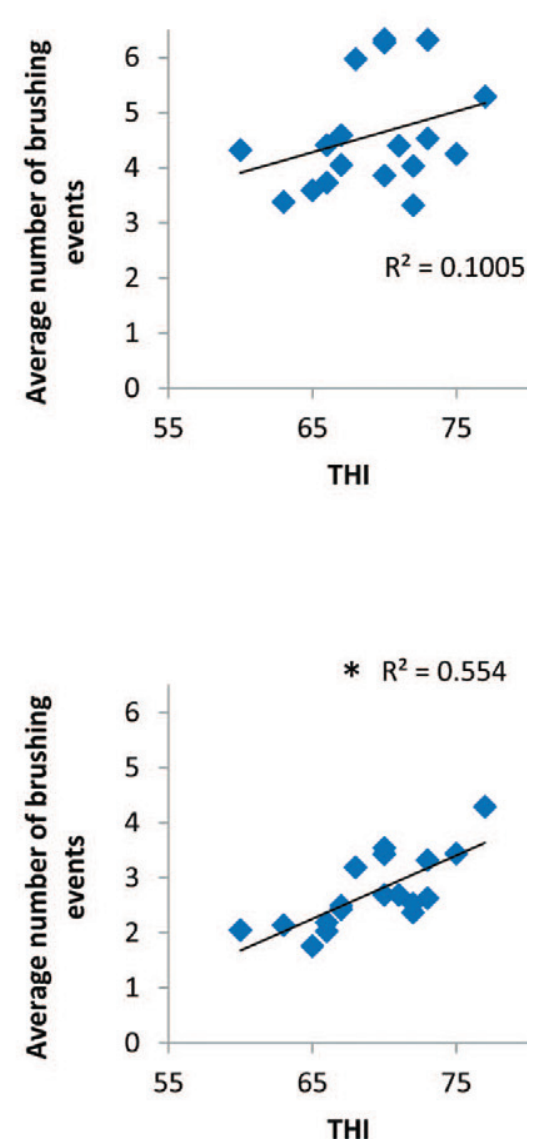

Figure 3. The effect of temperature and humidity index (THI) on the average number of brushing events per day. Average number of brushing events during daytime $(0600-1800 \mathrm{~h})$ and nighttime $(1800-0600 \mathrm{~h})$ using Pearson correlation procedure. ${ }^{*} P<0.01$. Color version available in the online PDF. 

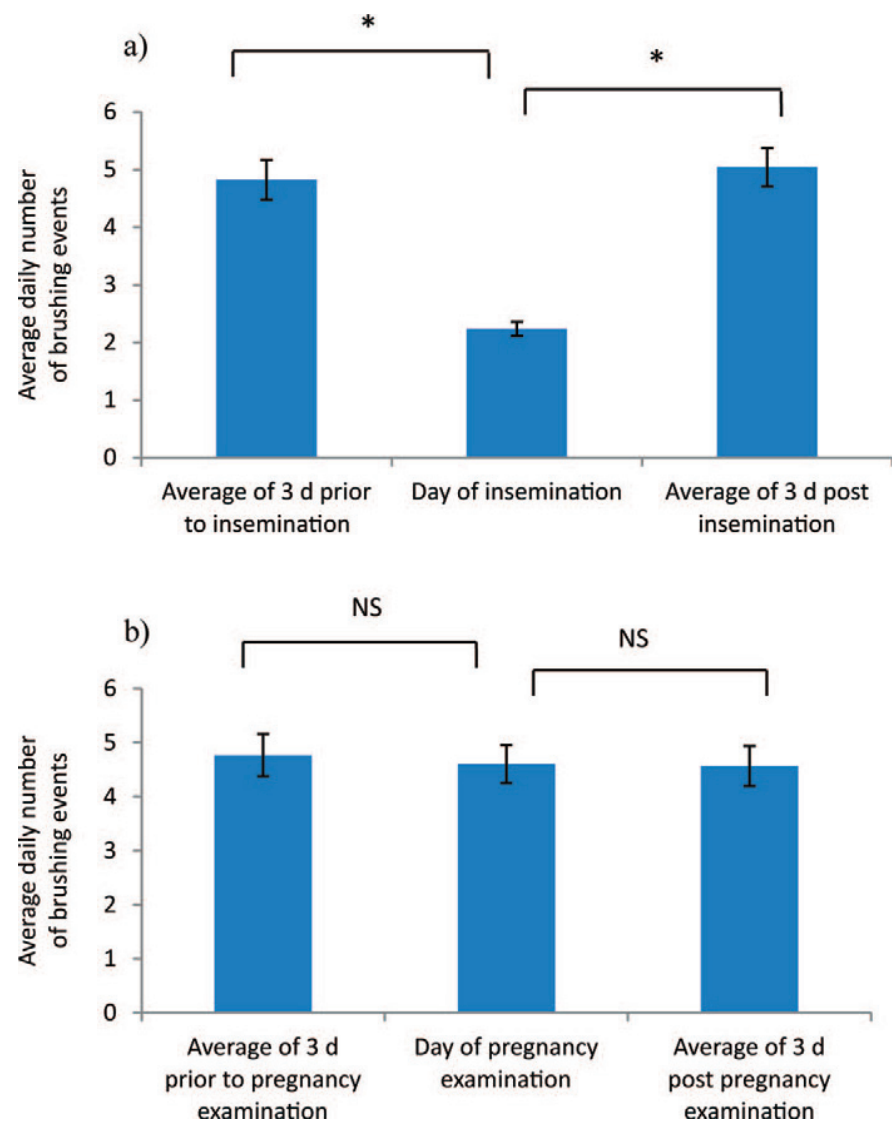

Figure 4. The effect of (a) AI, and (b) pregnancy examination on brush usage. Bars represent standard error of the means. ${ }^{*} P<0.05$. Color version available in the online PDF.

Although we did not predict this result, a possible explanation may be the effect of temperature and humidity on the behavior of dairy cows during the night. Following high temperatures during the day, cows are involved in compensatory nighttime feeding (Richards, 1985) and spend less time lying (Overton et al., 2002). Thus, increased THI levels during the day may have been associated with increased nighttime activity around the food location, resulting in more brushing activity on days when food was located near the brush. Further research is needed to understand the factors underlying this behavior.

Previous findings suggest that an intrusive medical procedure in the form of vaginal examination imposes stress on cows (Fischer-Tenhagen et al., 2012). Because stress consumes energy resources (Moberg, 2000), we hypothesized that brushing activity would be reduced on days of pregnancy examination or AI. In accordance with our hypothesis, the day of the stressful procedure was accompanied by a reduction of approximately $35 \%$ in brushing activity compared with the preceding and following 3 d. However, further analysis revealed that the association was mainly observed in relation to the AI process, and was not found on the day of pregnancy examination. One possible explanation is that pregnancy examinations might have been less stressful because they included only a rectal examination, whereas AI included both rectal and vaginal intrusions. Because we did not measure stress levels during pregnancy examination or AI, we cannot examine this possibility, and this issue will be investigated in future research. Another possibility is that the effect was related not to the stress involved in the intrusive procedures, but rather to behavioral changes related to estrus. The estrous period is characterized by increased movement and exploration (Kiddy, 1977; Van Vliet and Van Eerdenburg, 1996), which may result in less time available for other activities such as brushing. It is important to note that, although cows were provided with food and water during the AI process, we cannot entirely exclude the effect of the procedure on the cows' time budget, because the procedure interfered with lying behavior during this period.

Another limitation of using brushing activity as a measure is the fact that the use of the brush by one cow may influence the use by another and brush usage might have been affected by social facilitation (Phillips, 2000 ) by the surrounding cows. The brush is a single resource shared by all the cows in the herd; thus, at any given time, brushing activity of a certain cow may influence the brushing (or nonbrushing) of other cows. This dependence, which derives from the need to compete for the brush with other cows, is indeed a limitation. However, it may also be considered as part of the cost involved in this activity. In this view, such competition might make this tool even more sensitive to morbidityrelated energy decreases, because sick cows may have less energy not only to approach to the brush but also to compete for it with other cows.

\section{CONCLUSIONS}

Monitoring brushing activity allowed us to detect changes in cow behavior following changes in food location, during heat load, and on the day of AI. Reduction of brush usage because of heat load was more prominent when food was located farther from the brush; that is, when approaching the brush required a greater investment of effort and energy. Our study was conducted in a single herd and focused mainly on routine procedures conducted on the dairy farm. Further research should be conducted to assess the sensitivity and specificity of this suggested tool for early detection of morbidity. 


\section{ACKNOWLEDGMENTS}

This research was supported by the Universities Federation for Animal Welfare (Hertfordshire, UK) and by the Harry and Sylvia Hoffman Leadership and Responsibility Program at the Hebrew University (Jerusalem, Israel).

\section{REFERENCES}

Almeida, P. E., P. S. D. Weber, J. L. Burton, and A. J. Zanella. 2008. Depressed DHEA and increased sickness response behaviors in lame dairy cows with inflammatory foot lesions. Domest. Anim. Endocrinol. 34:89-99.

Borderas, T. F., A. M. de Passillé, and J. Rushen. 2008. Behavior of dairy calves after a low dose of bacterial endotoxin. J. Anim. Sci. 86:2920-2927.

Cabib, S., and S. Puglisi-Allegra. 1996. Stress, depression and mesolimbic dopamine system. Psychopharmacology (Berl.) 128:331-342.

Collier, R. J., and R. B. Zimbelman. 2007. Heat stress effects on cattle: What we know and what we don't know. Pages 76-832 in Proc. 2nd Annu. Southwest Nutrition and Management Conf., Tempe, AZ. Univ. of Arizona, Tucson.

Dawkins, M. S. 1990. From an animal's point of view: Motivation, fitness, and animal welfare. Behav. Brain Sci. 13:1-9.

DeVries, T. J., M. Vankuva, D. M. Veira, and M. A. G. von Keyserlingk. 2007. Short communication: Usage of mechanical brushes by lactating dairy cows. J. Dairy Sci. 90:2241-2245.

Fischer-Tenhagen, C., M. Pliz, and W. Heuwieser. 2012. Assessment of stress responses and heart rate during vaginal examination in dairy cows. Page 62 in Proc. Dairy Cattle Welfare Symp., Guelph, Ontario, Canada. Omnipress, Madison, WI.

Fogsgaard, K. K., C. M. Røntved, P. Sørensen, and M. S. Herskin. 2012. Sickness behavior in dairy cows during Escherichia coli mastitis. J. Dairy Sci. 95:630-638.

Fraser, D., and C. J. Nicol. 2010 Preference and motivation research. Pages 183-199 in Animal Welfare. 2nd ed. M. Appleby, ed. CABI, Wallingford, UK.

Georg, H., D. Jahn-Falk, and G. U. Brunswick. 2007. Technology against boredom. Landtechnik 62:166-167.

Georg, H., and K. Totschek. 2001. Investigation of an automated brush for dairy cows. Landtechnik 56:260-261.

Kiddy, C. A. 1977. Variation in physical activity as an indication of estrus in dairy cows. J. Dairy Sci. 60:235-243.

Littin, K., A. Acevedo, W. Browne, J. Edgar, M. Mendl, D. Owen, C. Sherwin, H. Würbel, and C. J. Nicol. 2008. Towards humane end points: Behavioural changes precede clinical signs of disease in a Huntington's disease model. Proc. Biol. Sci. 275:1865-1874.
McFarland, D. 1999. Animal Behaviour. 3rd ed. Addison Wesley Longman, Reading, UK.

Meagher, R. K., and G. J. Mason. 2012. Environmental enrichment reduces signs of boredom in caged mink. PLoS ONE 7:e49180.

Moberg, G. P. 2000. Biological response to stress: Implications for animal welfare. Pages 1-22 in The Biology of Animal Stress: Basic Principles and Implications for Animal Welfare. 1st ed.. G. P. Moberg, and J. A. Mench, ed. CABI Publishing, Wallingford, UK.

Newby, N. C., T. F. Duffield, D. L. Pearl, K. E. Leslie, S. J. LeBlanc and M. A. G. von Keyserlingk. 2013. Short communication: Use of a mechanical brush by Holstein dairy cattle around parturition. J. Dairy Sci. 96:2339-2344.

Ominski, K. H., A. D. Kennedy, K. M. Wittenberg, and S. A. Moshtaghi-Nia. 2002. Physiological and production responses to feeding schedule in lactating dairy cows exposed to short-term, moderate heat stress. J. Dairy Sci. 85:730-737.

Overton, M. W., W. M. Sischo, G. D. Temple, and D. A. Moore. 2002. Using time-lapse video photography to assess dairy cattle lying behavior in a freestall barn. J. Dairy Sci. 85:2407-2413.

Phillips, C. J. C. 2000. Further aspects of the use of individual animals as replicates in statistical analysis. Appl. Anim. Behav. Sci. 69:85-88.

Relić, R., S. Hristov, M. Joksimović-Todorović, V. Davidović, and J Bojkovski. 2012. Behavior of cattle as an Indicator of their health and welfare. Bull. USAMV Ser. Vet. Med. 69:1-2.

Richards, J. I. 1985. Milk production of Friesian cows subjected to high daytime temperatures when allowed food either ad lib or at night-time only. Trop. Anim. Health Prod. 17:141-152.

Rushen, J., N. Chapinal, and A. M. de Passillé. 2012. Automated monitoring of behavioural-based animal welfare indicators. Anim. Welf. 21:339-350.

Schukken, Y. H., and G. D. Young. 2009. Field study on milk production and mastitis effect of the DeLaval Swinging Cow Brush. DeLaval Swinging Cow Brush Study Final Report, August 5. DeLaval, Tumba, Sweden.

Val-Laillet, D., D. M. Veira, and M. A. G. von Keyserlingk. 2008. Short communication: Dominance in free-stall-housed dairy cattle is dependent upon resource. J. Dairy Sci. 91:3922-3926.

Van Vliet, J. H., and F. J. C. M. Van Eerdenburg. 1996. Sexual activities and oestrus detection in lactating Holstein cows. Appl. Anim. Behav. Sci. 50:57-69.

Verbeek, E., J. R. Waas, L. McLeay, and L. R. Matthews. 2011. Measurement of feeding motivation in sheep and the effects of food restriction. Appl. Anim. Behav. Sci. 132:121-130.

Weary, D. M., J. M. Huzzey, and M. A. G. von Keyserlingk. 2009. Board-Invited Review: Using behavior to predict and identify ill health in animals. J. Anim. Sci. 87:770-777.

Wilson, S. C., F. M. Miltohner, J. Morrow-Tesch, J. W. Dailey, and J. J. McGlone. 2002. An assessment of several potential enrichment devices for feedlot cattle. Appl. Anim. Behav. Sci. 76:259-265. 